\title{
Research on Taoist Daily Clothing in Han and Tang Dynasties
}

\author{
Rong Yang ${ }^{1} \&$ Xiaoming Yang ${ }^{2}$ \\ ${ }^{1}$ College of Humanities, Donghua University, Songjiang, Shanghai, China \\ Correspondence: Xiaoming Yang, College of Humanities, Donghua University, Songjiang, Shanghai, 201620, \\ China. E-mail: ynide@sina.com
}

Received: April 2, $2020 \quad$ Accepted: April 26, $2020 \quad$ Online Published: April 30, 2020

doi:10.5539/ass.v16n5p92

URL: https://doi.org/10.5539/ass.v16n5p92

\begin{abstract}
From the perspective of the form of Taoist daily clothing in the early Han Dynasty, Sui and Tang Dynasties was the beginning of the secularization of Taoist clothing. In the Five Dynasties, taking the legal clothing as the prototype, the secular Taoist clothing "Beizi" was derived, which made the Taoist clothing no longer belong to the exclusive use of the ruling class and Taoists, and finally made it secularized.
\end{abstract}

Keywords: Taoism clothing, Taoist daily clothing, Han and Tang dynasties

The regular clothes in Taoist clothing are the daily clothing worn by Taoists, and their form is based on the principle of simplicity, which embodies the connotation of "dress shabbily in order to hide one's real worth ". All the literati wear Taoist clothing (Taoists' regular clothes). Therefore, Taoist daily clothing and secular clothing influence each other and become an indispensable part of secular clothing in the future.

\section{The End of Han Dynasty}

The clothing of Taoist groups in early ancient times were not specially customized. The well-known peasant uprising of "TaiPing Dao" in Eastern Han Dynasty, Zhang Jiao wears a "yellow scarf". ShiMing said, "Twenty adults wears crowns, common people wears towels." ([Han] Liu Xi, Vol. 4, p. 41) Thus it can be seen that the ancient crowns were only worn by the upper class, and ordinary people could only wear towels. Therefore, the headdress in the earliest Taoist group "Yellow scarf uprising" was made up of the "yellow scarf" of the civilian class.

Then, HanShu said, "Zhang Lu ordered his subordinates to change their yellow scarf to represent the Han Dynasty...... Since then, yellow clothes have been on and on." In Hanzhong of "WuDouMi Dao". Zhang Lu dressed in "yellow clothes" made his subordinates change the "yellow towels", and their yellow clothes were consistent with the "yellow scarves" written by Zhang Jiao. It is also contained in GuanghongMingji: "since ZhangLu won Hanzhong, he killed Zhang Xiu, and wears a yellow scarf and wears yellow coarse clothes for a rebellious bandit". The material of "Yellow coarse clothes" is crude cloth, which is generally worn by ordinary people in the clothing system of the Han Dynasty. Huang Xianyu put forward in the "Study of the Evolution of clothing in China" said: "the length of a short jacket is no longer than the knee, and so is the cruse cloth.....A short jacket are both short and long ones, and the cruse cloth is not only the same as the one who uses it, but also the one who uses it..... Generally speaking, the length is less and the shorter is more, which is called short jacket." (Huang Xianyu, 2004, p. 234) And according to ShuoWenJieZi said, "He, weave stockings. One is coarse clothes. ", "Ru is short clothes." ([Han] Xu Shen, 1985, p. 274, 273) It can be seen from the above that in the Eastern Han Dynasty, the clothes of the early Taoist groups were all brown towels of common people, that is, wearing yellow scarves on the head and wearing yellow coarse clothes that could not go up to the knee.

\section{Wei, Jin, Southern and Northern Dynasties}

The common clothes in Taoist clothing are "scarves, he (Taoist robes), skirts and shoes" worn by Taoists. In terms of color, "Taoists often wear blue," ([Ming] Xu fu, Vol. 617, p. 618) and the shape is simple, with the purpose of " dress shabbily in order to hide one's real worth", it is not allowed to carve and decorate, and it is beautiful to be simple and natural. In the early days of Taoism, there was no special custom-made clothing, but it was mainly in the form of simple with "towel and robes".

During the period of Wei, Jin, southern and Northern Dynasties, due to the frequent social unrest and wars, most of the literati returned to seclusion and cultivation of Taoism, which made Taoism develop rapidly in the upper 
society and the rise of Taoism. His thought advocates "Wuwei and nature", emphasizes the nature of the self, and is far away from the secular material, so as to achieve the state of "unity of man and nature". And clothing is the social ideological and cultural display at that time, but also a complete embodiment of the immortal shape. In this period, the clothing system was "all of them were small crown at the end of Jin Dynasty, but their clothes shape were very large, and they were popular with each other." ([Yuan] Ma Duanlin, Vol. 616, p. 156) It can be seen that the scholar bureaucrats in the upper society, wearing this kind of clothes in the form of large sleeves, seem loose and elegant, which is different from the hierarchy of the current Dynasty. This kind of clothing style, which is back to the basics and not limited to small sections, instead reflects a kind of natural beauty, and also causes the fashion of dress decoration in the current Dynasty. This kind of shape of large sleeves can be seen in many scholars and princes.

For example, the clothes of The Seven Sages of the Bamboo Grove is not restricted by etiquette. They wear wide sleeved shirts, open collars, bare chests, scarves or hair, barefoot, and indulge in love songs and drinks. In Gu Kaizhi's painting of Ode to the God of Luo, Cao Zhi and his attendants wear the same style of clothes as those of The Seven Sages of the Bamboo Grove, all of which are handed over with large sleeved shirts on the right lapel. All of these show that the "big sleeved shirt" dress is very popular among scholars and scholar officials during the Wei and Jin Dynasties, and the shape of the big sleeved shirt also has a far-reaching impact on the popular Taoist dress in the later secular life.

\section{Sui, Tang and Five Dynasties}

During the Sui and Tang Dynasties, Taoist clothing were based on the daily clothing in the form of scarves and robes in the northern and Southern Dynasties. According to the "DongxuanLingbaoDaoxueKeyi" said: "If a Taoist, if a female Taoist, he usually practices Taoism and wears a ErYi scarf. There are two corners of the scarf, the scarf show of the Dao." (Dao ZANG, 1988, Vol. 24, p. 768) ErYi, according to the book of ZhouYi, said: "Taiji moves to produce Yang, while it is quiet to produce Yin. It is for LiangYi." ([Song] Yuyan, 1990, Vol. 29, p. 284) That is, the sun, the moon, the sky and the earth, as well as Yin and Yang. It is used by Taoists in their daily practice. The shape of the headdress should be tied into two corners behind the head. According to the shape of the ErYi scarves in the later Qing Dynasty, it is similar to that in the Sui and Tang Dynasties: "ErYi scarves, with two leaves flying behind." ([Qing] Chen Yuanlong, 1989, Vol.14, p. 130) In the form, they all stand out with two corners or two leaves. It can be seen that during the Sui and Tang Dynasties, the shape of Taoist's regular clothes was still the form of "towel and robes".

Then, in addition to the daily clothes "towel, robes" worn by Taoists, there was a kind of Robe system in the Sui and Tang secular clothing system (upper and lower general cutting system). That is to say, a piece of cloth is used to cut out the upper garment and the lower garment. There is no seam in the middle, which is obviously different from the upper garment and the lower garment system. This form originated in the Sui and Tang Dynasties, which was a pioneering work at that time, because since ancient times, Hanfu was made in the form of "top and bottom clothes". There are many kinds of general cut clothes in ancient times, such as round necked robes, ZhiZhui, Taosits robes, BeiZi, monk's clothes, etc. However, the forms of "ZhiZhui" and "BeiZi" are the most popular from Tang, song and Ming Dynasties, which are often inseparable from Taoist robes, and the form is evolved from Taoist clothing. These Taoist clothing can be worn daily from the Song Dynasty to the Ming Dynasty and the Qing Dynasty, from the princes and nobles to the common people. They are also popular among scholars.

In the Tang Dynasty, Taoism was greatly developed because of the emperor family of the ruling class regarded Laozi as their ancestor. Because Taoism is respected by the ruling class, Daofu is frequently used in the dress of the emperor and princes. In Tang Dynasty, princesses also wore Taoist clothing. For example, it is recorded in YouYangZaZu: "Princess Shou An, will born of CaoYe Naji in September, but she didn't come out. (Xuanzong) orders her mother worn Taosit clothes. It is the Lord of incense." ([Tang] Duan Chengshi, Vol. 1, p. 14) also "ChaoYeJinZai" said: "Taoist Shi Chongxuan attached Princess Taiping's purple skirt." ([Song] Pan Zimu, Vol. 932, p. 599) These records show that Taoism had a high position in the Tang Dynasty. Emperors, princesses were all believers in Taoism. They could not only show their religious beliefs, but also produce the function of praying for blessings and exorcising evil spirits. These religious functions of Daofu were naturally what everyone wanted to wear. However, during the Tang Dynasty, it was not only worn by ordinary secular people, but only by the ruling class and Taoists in the upper society.

To the Five Dynasties, Taoist clothing is no longer the exclusive clothing of the ruling class and Taoists, but can be worn by singing and dancing palace prostitutes in the harem, and it is an honor to wear Taoist clothing. Among them, the Shu king of Wang Yan played an important role in the secularization of Taoist clothing. 
According to "ShuZhongGuangJi" said: "the Shu king of Wang Yan wear a small hat, only to cover its top......said that the dangerous brain hat derivative thought ominous......every micro-suit to travel to the people, with a big hat to know it. So everyone wears a big hat and a scarf, which is shaped like a cone, while the harem all wear a golden lotus crown, a Taoist clothing...... which is effective for all the people in the country." ([Ming] Cao Xuequan, Vol. 591, p. 741) Wang Yan ordered the harem to wear lotus crowns and Taoist clothes, causing everyone to follow. It can be seen that Taoist clothing has gradually become a popular dress in the secular society during the Five dynasties.Among them, the lotus crown was originally worn by the Dharma Master in the Taoist and religious clothing. SanDongFaFuKeJieWen recorded that the "crown is like a lotus or two leaves on four sides" (Dao Zang, 1988, Vol. 18, p. 229) by the Dharma Master DongXuan, and the "Lotus crown or three leaves on four sides, is called YuanShi crown" (Dao Zang, 1988, Vol. 18, p. 229) by the Dharma Master DongZhen. In the Five Dynasties, the lotus crown has been popular among the common people's clothing, especially among the female groups. Tang Yin of the Ming Dynasty drew a picture of this move of the Shu king: the palace prostitutes wore Golden Lotus crown, Taoist clothes. The lotus crown is shaped like a petal, which is buckled in a bun separately, while the DaoFu is the shape of a BeiZi. In the later Shu Dynasty, the same shape of the crown also appeared in the female opera figures with a crown unearthed from Zhao Tingyin's tomb. Among them, there are 5 female figurines wearing a crown, and 2 of them are lotus shaped Taoist crowns.

It can be seen that the lotus crown of Taoist in the Tang Dynasty has developed towards the trend of secularization, and it is often worn by women. In this period, the hairpin is vertical, that is, the Ziwu hairpin from the front to the back is fixed. This way of wearing is also in accordance with the Taoist clothing system. However, it can be seen from the paintings and unearthed objects that the lotus crown after secularization is slightly different from the lotus crown in Taoist clothing. For example, the lotus crown in Taoist clothing pays attention to the number of petals, which corresponds to different levels of Taoists, and ordinary Taoists cannot wear it. From the perspective of the lotus crown in the secular world, its main function is decoration. The wearer can be regardless of the status, which virtually weakens the religious function of the lotus crown and makes it closer to the secular society. The change of form and function also shows that the influence of DaoFu on the secular clothing in the Five Dynasties is more in-depth.

The Taoist clothing worn by women in "The Map of the Palace Prostitute in the Shu of the Kings" is a BeiZi popular in the Tang and Song Dynasties. The shape of the shuttlecock is that the lapels are non-intersecting, the collar edge extends to the hem of the clothes, straight up and down, slits on both sides, and narrow sleeves. "Since the Northern Dynasty, men's and women's clothing has been decorated with long sleeves, with narrow sleeves.In the early Tang Dynasty, and it was a little bit bosom after the KaiYuan period ... It is said that since the Six Dynasties to the early Tang Dynasty, both men and women wear Hu clothing ... Women's clothing is also the same and slightly longer, inside there are also long skirts, shawls and scarves ... which shows that the clothing of the Li and Tang generations has changed." (Ceng Zhongmian, 1982, p. 679) It can be seen that the clothes made of narrow sleeves were influenced by ethnic minorities, and they were very popular during the Sui and Tang Dynasties. Although the DaoFu has always been shaped by the large-sleeved cross-neck of the Han Dynasty clothing, the female DaoFu is a narrow-sleeved placket collar. Regarding this form of female clothes, Zhang Beibei said in the article "Discussion on the Origin and Development of Women's Clothes Mules":"The external characteristics and cultural meaning of women's clothes BeiZi are derived from female Taoists clothing, but it is not a simple copy and misappropriation, its on the basis of absorbing the clothing style of the female Taoists clothing, make some changes in the style of BeiZi." (Zhang Beibei, 2014, Vol. 4, p. 145) Therefore, BeiZi is also a fusion of the minority costumes of the Sui and Tang dynasties and the female Taoists clothing of the Five Dynasties. It is a manifestation of secular clothing.

In this period, in addition to the above-mentioned prostitutes wearing DaoFu, it was also popular among the literati. In the history of the Old Five Dynasties, it is recorded that: "(Lu) Cheng visited Yan, Zhao and wear Taoist clothing." ([Song] Xue Juzheng, 1976, Vol. 67, p. 887) It can be seen that in the secular society, there are people wearing DaoFu at all levels, and the period of Five Dynasties has also become an important period of DaoFu secularization.

\section{Conclusion}

To sum up, the Sui, Tang and Five Dynasties was the beginning of secularization of Daoist clothing, which was largely advocated by the ruling class of the upper society. Therefore, clothing culture cannot be separated from the support of social religion. In the Sui and Tang Dynasties, DaoFu was mostly worn by the upper ruling class. Only in the Five Dynasties, DaoFu gradually form a social fashion and become a part of secular clothing. 


\section{References}

[Han] Liu, X. (1984). ShiMing. (Vol. 4, p. 41) Zhong Hua Book Company.

[Han] Xu, S. (1985). ShuoWenJieZi (p. 273, 274). Zhong Hua Book Company.

[Ming] Cao, X. Q. ShuZhongGuangJi (Vol. 591, p. 741). Taipei: Taiwan business press photocopies the complete book of Siku by wenyuange.

[Ming] Xu, F. MingHuiDian (p. 617, 618). Taipei: Taiwan business press photocopies the complete book of Siku by wenyuange.

[Qing] Chen, Y. L. (1989). GeZhiJingYuan (Vol. 14, p. 130). Jiangsu Guangling ancient book printing society.

[Song] Pan, Z. M. JiZuanYuanHai (Vol. 932, p. 599). Taipei: Taiwan business press photocopies the complete book of Siku by wenyuange.

[Song] Xue, J. Z. (1976). Old Five-Dynasties History (Vol. 67, p. 887). Zhong Hua Book Company.

[Song] Yu, Y. (1990). ZhouYiJiShuob (Vol. 29, p. 284). Shanghai Classics Publishing House.

[Tang] Duan, C. S. YouYangZaZu (Vol. 1, p. 14). Four part series, Shanghai Hanfen tower, cangming Edition.

[Yuan] Ma, D. L. WenXianTongKao (Vol. 616, p. 156). Taipei: Taiwan business press photocopies the complete book of Siku by wenyuange.

Ceng, Z. M. (1982). History of Sui and Tang Dynasties (p. 679). Zhong Hua Book Company.

DaoZang. (1988).Vol. 18 (p. 229). Cultural Relics Publishing House, Shanghai Bookstore Publishing House, Tianjin Ancient Books Publishing House.

DaoZang. (1988).Vol. 24 (p. 768). Cultural Relics Publishing House, Shanghai Bookstore Publishing House, Tianjin Ancient Books Publishing House.

Zhang, B. B. (2014). An analysis of the origin and development of the shape and system of Beizi. National Arts, (4), 145.

\section{Copyrights}

Copyright for this article is retained by the author(s), with first publication rights granted to the journal.

This is an open-access article distributed under the terms and conditions of the Creative Commons Attribution license (http://creativecommons.org/licenses/by/4.0/). 